\title{
Comparative efficacies of imipenem, oxacillin and vancomycin for therapy of chronic foreign body infection due to methicillin-susceptible and -resistant Staphylococcus aureus
}

\author{
Heinz J. Schaad*, Christian Chuard $\dagger$, Pierre Vaudaux $\ddagger$, Peter Rohner, \\ Francis A. Waldvogel and Daniel P. Lew \\ Division of Infectious Diseases, University Hospital, Geneva, Switzerland
}

\begin{abstract}
The efficacies of imipenem when directed against methicillin-susceptible (MSSA) and methicillin-resistant (MRSA) strains of Staphylococcus aureus were compared with those of oxacillin and vancomycin in a subcutaneous rat model, using chronically infected tissue cages. At three weeks after inoculation, stable chronic infections were established with average bacterial counts exceeding $10^{6} \mathrm{cfu} / \mathrm{mL}$ tissue cage fluid for both strains. Intraperitoneal administration (twice a day for 7 days) of imipenem $(80 \mathrm{mg} / \mathrm{kg})$ or oxacillin $(200 \mathrm{mg} / \mathrm{kg})$ produced peak levels of 23 or $45 \mathrm{mg} / \mathrm{L}$ and trough levels of $<0.1$ and $5.7 \mathrm{mg} / \mathrm{L}$, respectively. The therapeutic regimens of either imipenem $(P<0.001)$ or oxacillin $(P<0.02)$ administered for 7 days led to significant reductions in bacterial counts in the tissue cage fluids of animals chronically infected with MSSA. In contrast, imipenem was not effective against chronic MRSA tissue cage infections, despite the relatively low MIC of the infecting strain and the use of high dose $(120 \mathrm{mg} / \mathrm{kg})$ therapy. In-vitro susceptibility testings of MRSA performed before and after imipenem therapy demonstrated the emergence of a highly resistant subpopulation.
\end{abstract}

\section{Introduction}

Foreign body infections are a major source of patient morbidity and implant failure. They can affect not only orthopaedic prostheses but also intravascular catheters and artificial heart valves (Bisno, 1989; Brause, 1989; Karchmer \& Bisno, 1989). Several clinical and experimental studies have documented the frequent failure of antimicrobial agents to eradicate staphylococcal infections associated with foreign implants or devices (Bisno, 1989; Brause, 1989; Karchmer \& Bisno, 1989). The reasons for this lack of effectiveness are still poorly understood and may involve alterations in the surfaces of the bacteria colonizing implants (Gristina \& Costerton, 1985; Chuard et al., 1991b), impairment in the host defense mechanisms (Zimmerli, Lew \& Waldvogel, 1984; Vaudaux, Lew \& Waldvogel, 1989), or both.

\footnotetext{
* Present address: Division of Clinical Pharmacology, Johns Hopkins University School of Medicine, Baltimore, Maryland, USA.

†Present address: Laboratory of Clinical Microbiology, Duke University Medical Center, Durham, NC 27710, USA.

$\ddagger$ Corresponding author: P. Vaudaux, Division of Infectious Diseases, University Hospital, 1211 Geneva 14, Switzerland.
} 
To screen for new agents or to test new regimens for effective therapy of chronic foreign body infections, we recently developed a rat model of subcutaneous foreign body infection. This model has provided useful information in showing the advantage of combination therapy over monotherapy, over periods of 1 (Lucet et al., 1990) to 3 weeks (Chuard et al., 1991a).

Imipenem is a highly active, broad-spectrum antibiotic with good tissue penetration (Drusano, 1986; Wise et al., 1986) and a low frequency of side effects (Calandra et al., 1986). Imipenem is extremely resistant to the staphylococcal $\beta$-lactamase and shows high activity against methicillin-susceptible strains of Staphylococcus aureus (Witte, Sapico \& Canawati, 1982). The first aim of this study was to evaluate the efficacy of imipenem, as compared to oxacillin, in the experimental model of chronic tissue cage infection by a methicillin-susceptible strain of $S$. aureus. The second objective was to evaluate the response of a heterogeneous methicillin-resistant strain of $S$. aureus to a high dose imipenem therapy and compare this to the response to vancomycin in the tissue cage model of chronic infection, because, although the use of imipenem against methicillin-resistant strains is not recommended (Chambers, 1988; Brumfitt \& Hamilton-Miller, 1989), determination of its efficacy in vivo in the clinical situation (Fan et al., 1986) and in animal models of infections by methicillin-resistant strains of staphylococci has yielded conflicting data (Berry, Johnston \& Archer, 1986; Chandrasekar et al., 1988).

\section{Materials and methods}

\section{Antimicrobial agents and media}

For in-vitro studies, laboratory standards of the antimicrobials used with known potency were supplied as follows: imipenem by Merck Sharp \& Dohme-Chibret, USA, oxacillin by Sigma, USA, and vancomycin by Eli Lilly, Germany. For animal studies, a $1: 1$ ratio of imipenem and cilastatin, (Tienam, Merck Sharp \& Dohme-Chibret, Switzerland) and vancomycin (Eli Lilly, Germany) were used and were dissolved in solvents as recommended by their manufacturers. Oxacillin (Sigma) was freshly dissolved in distilled water at a concentration of $20 \mathrm{mg} / \mathrm{mL}$.

A single batch of Mueller-Hinton broth (Difco, USA), with low contents of $\mathrm{Ca}^{2+}$ $(16 \mathrm{mg} / \mathrm{L})$ and $\mathrm{Mg}^{2+}(7 \mathrm{mg} / \mathrm{L})$, was used. To estimate antibacterial activity in vitro, Mueller-Hinton broth was supplemented (MHB-S) with $\mathrm{Ca}^{2+} 50 \mathrm{mg} / \mathrm{L}$ and $\mathrm{Mg}^{2+}$ $25 \mathrm{mg} / \mathrm{L}$. When indicated, MHB-S was supplemented with $2 \% \mathrm{NaCl}(\mathrm{w} / \mathrm{v})$.

\section{Bacteria}

The methicillin-susceptible (MSSA) and methicillin-resistant (MRSA) strains of $S$. aureus used for the animal studies were MSSA strain I20 (Chuard et al., 1991b) and MRSA multiresistant strain MRGR3 (Lucet et al., 1990). Both strains were isolated from patients with catheter-related sepsis and were selected for their virulence properties in the rat model of chronic tissue cage infections. Strain MRGR3 is resistant to methicillin and shows additional resistances to benzylpenicillin, gentamicin, chloramphenicol, erythromycin, tetracycline and polymyxin B.

One hundred and seven strains of $S$. aureus isolated at the University Hospital of Geneva were also tested for in-vitro susceptibility to imipenem. They comprised 57 MSSA and 50 MRSA strains. 


\section{In-vitro studies}

The MICs of imipenem for the 107 clinical isolates of $S$. aureus were determined by a previously described agar dilution method (Rohner et al., 1992). The medium used was Mueller-Hinton agar (Oxoid, Basingstoke, UK) and plates were inoculated with $10^{4} \mathrm{cfu}$ as previously described (Rohner et al., 1992). The MIC was determined as the lowest concentration of imipenem which completely inhibited growth, disregarding a single colony or a faint haze of growth.

The MICs and MBCs of imipenem and oxacillin for MSSA strain I20 and of imipenem and vancomycin for MRSA strain MRGR3 were determined by a macrodilution broth method using MH-S medium as indicated above and a standard inoculum of $10^{6} \mathrm{cfu} / \mathrm{mL}$. MIC tests were read after $24 \mathrm{~h}$ or, when indicated, after $48 \mathrm{~h}$ incubation at $37^{\circ} \mathrm{C}$. To test for possible carry-over effects of each antibiotic during $\mathrm{MBC}$ determinations, $0.1 \mathrm{~mL}$ portions were taken from all tubes with no visible growth. These were subcultured, either undiluted or serially diluted 10 -fold in saline, on Mueller-Hinton agar (Difco) for $24 \mathrm{~h}$ or, when indicated, for $48 \mathrm{~h}$ at $35^{\circ} \mathrm{C}$. The $\mathrm{MBC}$ was defined as the lowest concentration of antibiotic that killed $99.9 \%$ of the original inoculum (National Committee for Clinical Laboratory Standards, 1987). For MRSA strain MRGR3, MICs and MBCs were also tested in MH-S broth supplemented with $2 \% \mathrm{NaCl}$.

Time kill studies were performed with antibiotic concentrations corresponding to those found in tissue cage fluid (TCF), namely oxacillin $8 \mathrm{mg} / \mathrm{L}$ with MSSA and imipenem $8 \mathrm{mg} / \mathrm{L}$ or vancomycin $8 \mathrm{mg} / \mathrm{L}$ with MRSA. These levels are equivalent to 8-16 times the MICs for the respective strains. A much lower concentration $(0.2 \mathrm{mg} / \mathrm{L})$ of imipenem, equivalent to ten-times its MIC for MSSA, was used for time kill studies with this strain to avoid significant carryover effects. Glass tubes containing $10 \mathrm{~mL}$ of Mueller-Hinton broth were inoculated to a cell density of $10^{6} \mathrm{cfu} / \mathrm{mL}$ from a culture that had been grown exponentially for $3 \mathrm{~h}$, in a shaking waterbath at $37^{\circ} \mathrm{C}$. The number of viable organisms was determined by spreading $0.05 \mathrm{~mL}$ of ten-fold serially diluted portions of culture on Mueller-Hinton agar after $0,2,4,6$ and $24 \mathrm{~h}$ incubation. Bacteria were spread wth a spiral plater (Spiral System, Cincinnati, USA) and colonies counted with a laser colony counter (Spiral System) after $24 \mathrm{~h}$ incubation at $37^{\circ} \mathrm{C}$. The detection limit was $2 \log _{10} \mathrm{cfu} / \mathrm{mL}$ with all antibiotics tested. Comparison of viable counts obtained with the ten-fold serially diluted portions following a procedure previously described in detail (Lucet et al., 1990; Chuard et al., 1991a, 1992) indicated the absence of significant carryover of antibiotics under these experimental conditions.

\section{Treatment of chronic foreign body infections}

Animal experiments received the approval of the Ethical Committee of the University Hospital and of the State Veterinarian Office of Geneva. Four polytetrafluorethylene (Teflon) tissue cages were implanted subcutaneously in each Wistar rat as described previously (Lucet et al., 1990). At three weeks after implantation, a $50 \mu \mathrm{L}$-portion of the fluid that had accumulated (approximate volume: $1 \mathrm{~mL}$ ) in each cage (designated tissue cage fluid) was aspirated and checked for sterility. Then the cages were inoculated with $0.1 \mathrm{~mL}$ of saline containing $0.2 \times 10^{6}$ to $2 \times 10^{6} \mathrm{cfu}$ of MSSA or MRSA. Three weeks later, all tissue cages containing more than $1 \times 10^{5} \mathrm{cfu} / \mathrm{mL}$ TCF were included in the therapeutic protocol. Rats infected with MSSA were randomized to receive (by intraperitoneal route twice a day for 7 days) either imipenem $(80 \mathrm{mg} / \mathrm{kg})$ plus cilastatin, 
or oxacillin $(200 \mathrm{mg} / \mathrm{kg})$, or were left untreated. Rats infected with strain MRGR3 received (twice a day for 7 days) either imipenem $(120 \mathrm{mg} / \mathrm{kg})$ plus cilastatin, or vancomycin $(50 \mathrm{mg} / \mathrm{kg})$, or were left untreated. Twelve hours after the last injection of antibiotic, viable counts in 10-fold serially diluted TCF were obtained on Mueller-Hinton agar. Possible clumps of bacteria were disrupted by sonication of TCF for $1 \mathrm{~min}$ at $60 \mathrm{~W}$ (Branson 2200, Branson Ultrasonics, Danbury, USA) before plating. Quantitative bacterial counts were determined, with a detection limit of $100 \mathrm{cfu} / \mathrm{mL}$, and expressed as $\log _{10} \mathrm{cfu} / \mathrm{mL}$. For each cage, the difference between cfu counts from day 1 and day 8 were determined and expressed as delta $\log _{10} \mathrm{cfu} / \mathrm{mL}$.

For each group and treatment regimen, results were expressed as means \pm S.E.M. Comparisons of bacterial counts in the different groups were done using the nonparametric Kruskall-Wallis test and the Dunn procedure for comparison of specific groups (Rosner, 1990). Data were considered significant when $P$ was $<0.05$, using two-tailed significance levels.

\section{Pharmacokinetics of antimicrobial agents}

The pharmacokinetic properties of vancomycin in the TCF of rats were already known from previous studies (Lucet et al., 1990). Concentrations of imipenem and oxacillin in serum and TCF of non-infected animals were measured by bioassay at various time intervals ( $30 \mathrm{~min}, 1,2,4,6,8$ and $12 \mathrm{~h}$ ) after administration of the antibiotics. The test organism was a spore suspension of Bacillus subtilis. To prevent degradation of imipenem samples, serum or TCF were mixed with an equal volume of $1 \mathrm{~m}$ morpholineoethane sulfonate buffer (Fluka, Sargans, Switzerland) at pH6 and ethylene glycol (Fluka). In rats, the pharmacokinetics of imipenem and oxacillin were determined at both day 1 and day 7 of therapy.

\section{Results}

\section{Treatment of chronic MSSA tissue cage infections}

The MIC/MBC of oxacillin and imipenem for MSSA strain 120 were $0.5 / 1 \mathrm{mg} / \mathrm{L}$ and $0 \cdot 02 / 0.02 \mathrm{mg} / \mathrm{L}$, respectively. The MIC of imipenem for strain $\mathrm{I} 20$ fell within the range of MICs of a group of 57 clinical isolates of MSSA, all of which were inhibited by imipenem $0.06 \mathrm{mg} / \mathrm{L}$.

In time kill studies, incubation of MSSA with a low concentration $(0 \cdot 2 \mathrm{mg} / \mathrm{L})$ of imipenem, selected to avoid antibiotic carry over, resulted in a rapid in-vitro elimination of the bacteria by at least $3 \log _{10} \mathrm{cfu} / \mathrm{mL}$ within $4 \mathrm{~h}$. A similar decrease in viable counts was observed when the MSSA strain was exposed to oxacillin $8 \mathrm{mg} / \mathrm{L}$ (not shown).

Addition of $50 \%$ TCF to MHB-S medium, when estimating antibacterial activity in vitro, did not significantly modify the $\mathrm{MIC}$, the $\mathrm{MBC}$ or the bactericidal activity of each antibiotic compared with unsupplemented MHB-S medium (not shown).

During therapy with imipenem $(80 \mathrm{mg} / \mathrm{kg})$ plus cilastatin twice a day, average concentrations of imipenem peaked at $23 \mathrm{mg} / \mathrm{L}$ in rat TCF $2 \mathrm{~h}$ after administration. The rate of elimination of imipenem from TCF was rapid, with residual levels of 0.29 and $<0.1 \mathrm{mg} / \mathrm{L}$ after 8 and $12 \mathrm{~h}$, respectively. The pharmacokinetic properties of imipenem in TCF, which were similar at day 1 (not shown) and day 7 (Figure 1(a) indicated an average concentration of antibiotic exceeding the MIC for MSSA for a 

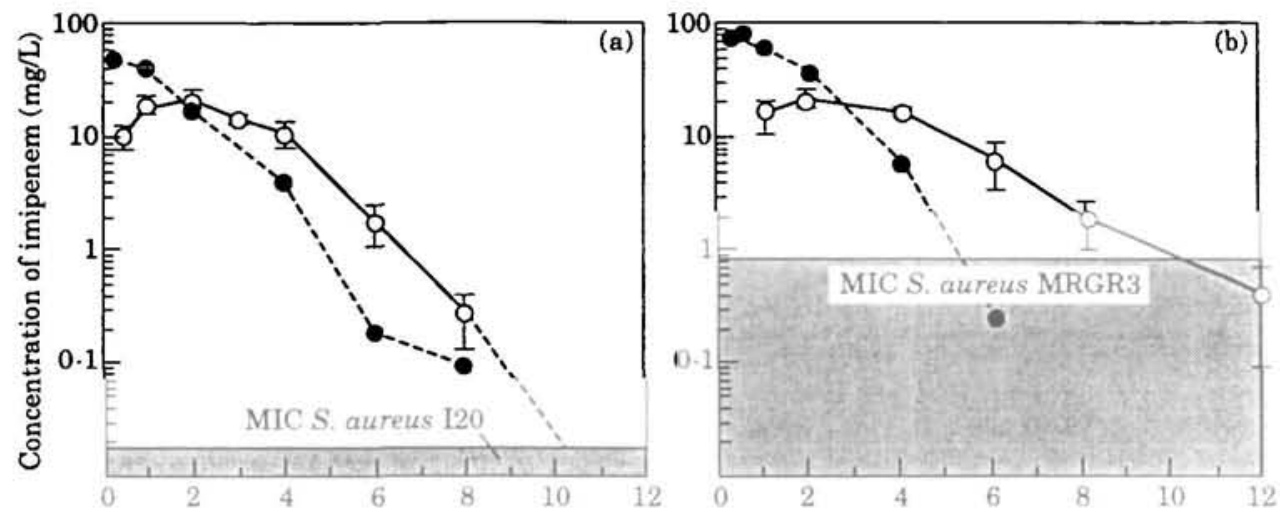

Time (h)

Figure 1. Concentration of imipenem in serum $(0)$ and tissue cage fluid $(O)$ of rats at day 7 after twice a day intraperitoneal administration of imipenem plus cilastatin. (a) Imipenem $80 \mathrm{mg} / \mathrm{kg}$ twice a day; (b) imipenem $120 \mathrm{mg} / \mathrm{kg}$ twice a day.

$10 \mathrm{~h}$-period during each 12-h cycle of therapy. In comparison, administration of oxacillin $(200 \mathrm{mg} / \mathrm{kg}$ twice a day) resulted in average TCF levels that continually exceeded the MIC for MSSA (peak: $45 \mathrm{mg} / \mathrm{L}$; trough: $5 \cdot 7 \mathrm{mg} / \mathrm{L}$ ).

Of 71 tissue cages inoculated with strain I20, 11 with bacterial counts less than $10^{5} \mathrm{cfu} / \mathrm{mL}$ TCF before the onset of therapy were excluded from the study. At day 1 , before antibiotic treatment, similar average bacterial counts were found in the fluids of the residual 60 tissue cages. The animals were subdivided into three groups with the following TCF counts: $6.85 \pm 0.27$ for the 19 cages of control rats, $6.58 \pm 0.18$ for the 23 cages of rats receiving imipenem, and $6.82 \pm 0.17 \log _{10} \mathrm{cfu} / \mathrm{mL}$ for the 18 cages of rats receiving oxacillin. At the end of the 7-day treatment period, cfu counts in TCFs of untreated animals increased slightly and non-significantly by $0.48 \pm 0.24 \log _{10} \mathrm{cfu} / \mathrm{mL}$ $(n=19)$. Both imipenem and oxacillin therapy led to significant decreases in viable counts of TCFs by $1.76 \pm 0.26(n=23, P<0.001)$ and $0.92 \pm 0.21 \quad(n=18, P<0.02)$ $\log _{10} \mathrm{cfu} / \mathrm{mL}$, respectively (Figure $2(\mathrm{a})$ ).

\section{Treatment of chronic MRSA tissue cage infection}

The MIC/MBC values of oxacillin and vancomycin for MRSA strain MRGR3 were $16 / 64$ and $1 / 2 \mathrm{mg} / \mathrm{L}$, respectively. In repeated experiments $(n=6)$, the MICs of imipenem for the MRSA strain MRGR3 ranged from $0 \cdot 125-1 \mathrm{mg} / \mathrm{L}$ and the MBCs from 16-32 mg/L. This MIC of imipenem for strain MRGR3 was at the lower end of the range of those obtained $(0.06$ to $>64 \mathrm{mg} / \mathrm{L})$ for a group of 50 clinical isolates of MRSA using agar dilution testing.

In time kill studies, MRSA strain MRGR3 exposed to imipenem $8 \mathrm{mg} / \mathrm{L}$ showed incomplete elimination of $1-2 \cdot 5 \log _{10} \mathrm{cfu} / \mathrm{mL}$ during the initial $6 \mathrm{~h}$, followed by partial regrowth thereafter. In similar conditions, vancomycin eliminated the test strain by $>3 \log _{10} \mathrm{cfu} / \mathrm{mL}$ at $24 \mathrm{~h}$ (data not shown).

To achieve TCF levels of imipenem active against MRSA strain MRGR3, a high dose regimen of $120 \mathrm{mg} / \mathrm{kg}$ was administered to infected animals twice a day for 7 days. This resulted in peak and trough levels of imipenem in TCF averaging 26 and $0.5 \mathrm{mg} / \mathrm{L}$, 

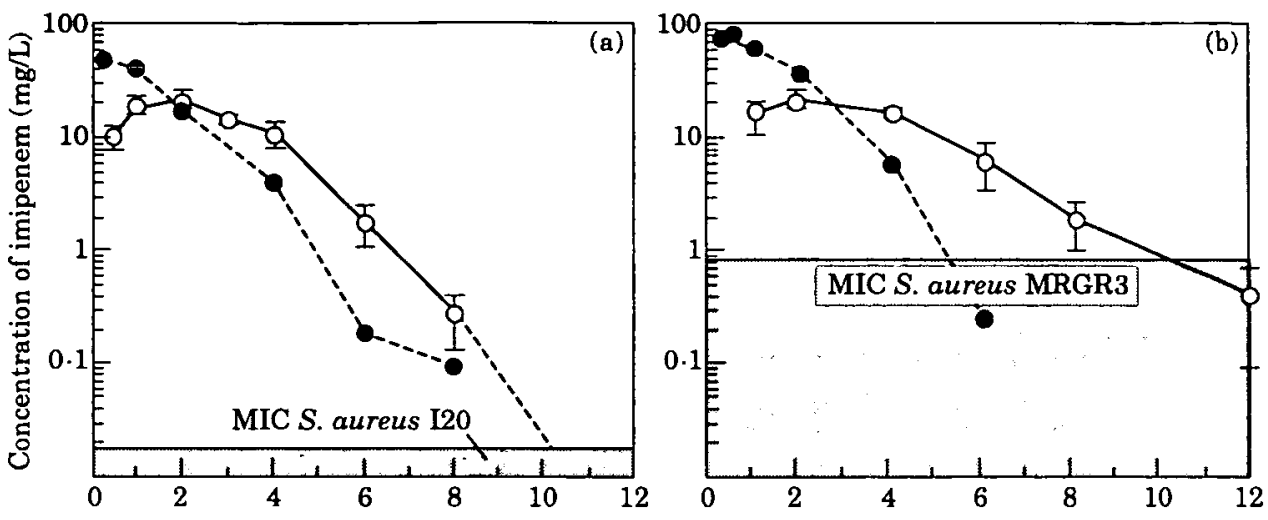

Time (h)

Figure 1. Concentration of imipenem in serum $(O)$ and tissue cage fluid $(O)$ of rats at day 7 after twice a day intraperitoneal administration of imipenem plus cilastatin. (a) Imipenem $80 \mathrm{mg} / \mathrm{kg}$ twice a day; (b) imipenem $120 \mathrm{mg} / \mathrm{kg}$ twice a day.

10 h-period during each 12-h cycle of therapy. In comparison, administration of oxacillin $(200 \mathrm{mg} / \mathrm{kg}$ twice a day) resulted in average TCF levels that continually exceeded the MIC for MSSA (peak: $45 \mathrm{mg} / \mathrm{L}$; trough: $5.7 \mathrm{mg} / \mathrm{L}$ ).

Of 71 tissue cages inoculated with strain 120,11 with bacterial counts less than $10^{5} \mathrm{cfu} / \mathrm{mL}$ TCF before the onset of therapy were excluded from the study. At day 1 , before antibiotic treatment, similar average bacterial counts were found in the fluids of the residual 60 tissue cages. The animals were subdivided into three groups with the following TCF counts: $6.85 \pm 0.27$ for the 19 cages of control rats, $6.58 \pm 0 \cdot 18$ for the 23 cages of rats receiving imipenem, and $6.82 \pm 0.17 \log _{10} \mathrm{cfu} / \mathrm{mL}$ for the 18 cages of rats receiving oxacillin. At the end of the 7-day treatment period, cfu counts in TCFs of untreated animals increased slightly and non-significantly by $0.48 \pm 0.24 \log _{10} \mathrm{cfu} / \mathrm{mL}$ $(n=19)$. Both imipenem and oxacillin therapy led to significant decreases in viable counts of TCFs by $1.76 \pm 0.26(n=23, P<0.001)$ and $0.92 \pm 0.21(n=18, P<0.02)$ $\log _{10} \mathrm{cfu} / \mathrm{mL}$, respectively (Figure $2(\mathrm{a})$ ).

\section{Treatment of chronic MRSA tissue cage infection}

The MIC/MBC values of oxacillin and vancomycin for MRSA strain MRGR3 were $16 / 64$ and $1 / 2 \mathrm{mg} / \mathrm{L}$, respectively. In repeated experiments $(n=6)$, the MICs of imipenem for the MRSA strain MRGR3 ranged from $0 \cdot 125-1 \mathrm{mg} / \mathrm{L}$ and the $\mathrm{MBCs}$ from 16-32 mg/L. This MIC of imipenem for strain MRGR3 was at the lower end of the range of those obtained $(0.06$ to $>64 \mathrm{mg} / \mathrm{L})$ for a group of 50 clinical isolates of MRSA using agar dilution testing.

In time kill studies, MRSA strain MRGR3 exposed to imipenem $8 \mathrm{mg} / \mathrm{L}$ showed incomplete elimination of $1-2 \cdot 5 \log _{10} \mathrm{cfu} / \mathrm{mL}$ during the initial $6 \mathrm{~h}$, followed by partial regrowth thereafter. In similar conditions, vancomycin eliminated the test strain by $>3 \log _{10} \mathrm{cfu} / \mathrm{mL}$ at $24 \mathrm{~h}$ (data not shown).

To achieve TCF levels of imipenem active against MRSA strain MRGR3, a high dose regimen of $120 \mathrm{mg} / \mathrm{kg}$ was administered to infected animals twice a day for 7 days. This resulted in peak and trough levels of imipenem in TCF averaging 26 and $0.5 \mathrm{mg} / \mathrm{L}$, 

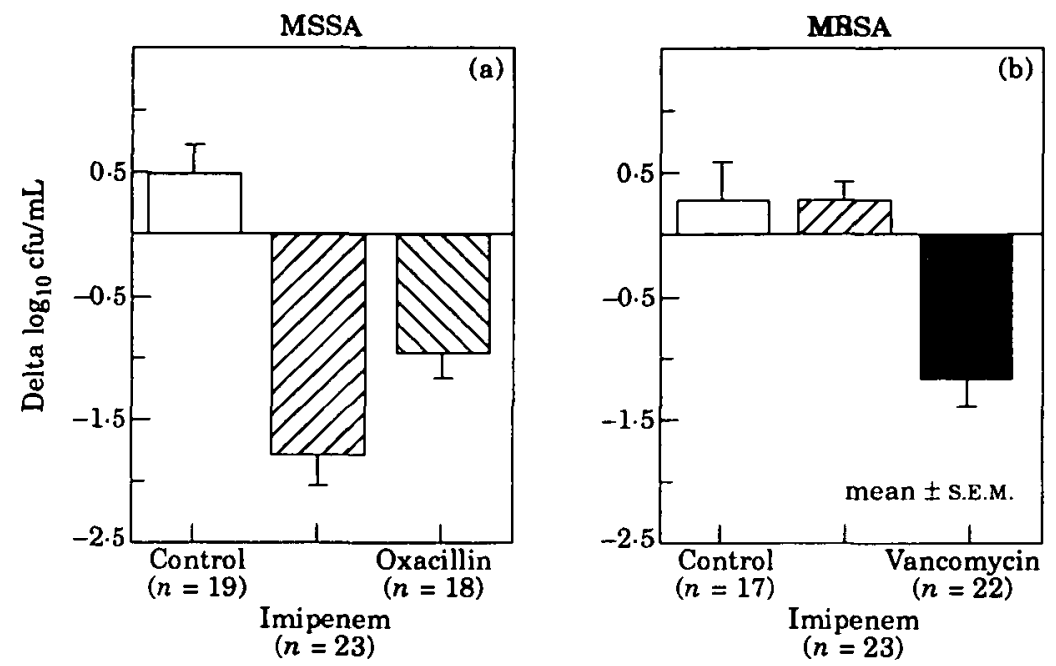

Figure 2. Reduction in bacterial counts of $S$. aureus in chronic tissue cage infection during a 7 day antimicrobial therapy. (a) Methicillin-susceptible strain I20; (b) methicillin-resistant strain MRGR3.

respectively, almost continuously exceeding the MIC for MRSA during therapy (Figure 1(b)). In comparison, animals receiving vancomycin $(50 \mathrm{mg} / \mathrm{kg})$ twice a day had average antibiotic levels that constantly exceeded the MIC for MRSA, with peak and trough levels of 12 and $2 \mathrm{mg} / \mathrm{L}$ at 4 and $12 \mathrm{~h}$, respectively.

For the comparative therapeutic trial, 78 cages were infected with MRSA strain MRGR3. Subsequently, 16 with inadequate bacterial counts were excluded from the study. At day 1, before therapy was started, average bacterial counts were similar in TCFs of untreated animals $(6.26 \pm 0.22 ; n=17)$ and those receiving imipenem $(6.33 \pm 0.20 ; n=23)$ or vancomycin $(6 \cdot 11 \pm 0.21 ; n=22)$. At the end of the seven-day treatment period, TCFs from vancomycin-treated animals showed a significant $(P<$ 0.002 ) decrease in their viable counts of $1.11 \pm 0.26 \log _{10} \mathrm{cfu} / \mathrm{mL}$ (Figure $2(\mathrm{~b})$ ). In contrast, high dose therapy with imipenem plus cilastatin did not lead to a reduction in TCF bacterial counts, but rather to a slight increase of $0.30 \pm 0.16 \log _{10} \mathrm{cfu} / \mathrm{mL}$, similar to that recorded in TCFs of untreated animals $\left(0.31 \pm 0.33 \log _{10} \mathrm{cfu} / \mathrm{mL}\right.$, Figure $\left.2(\mathrm{~b})\right)$.

To investigate further the lack of activity shown by imipenem for MRSA in tissue cage infections, additional in-vitro and in-vivo studies were performed. Various alterations in culture media and incubation conditions, known to influence expression of methicillin resistance, were made to determine the effects on the MIC of imipenem. These changes included addition of sodium chloride to the medium, a lower temperature of incubation, and an incubation time extended to $48 \mathrm{~h}$. Whereas adding $2 \% \mathrm{NaCl}$ to the medium or incubation at $30^{\circ} \mathrm{C}$ did not alter the $\mathrm{MIC}$ of imipenem for strain MRGR3 when the plates were read at $24 \mathrm{~h}$ (range from $0.125-1 \mathrm{mg} / \mathrm{L}$ in repeated experiments $(n=6)$ ), the MICs of imipenem were increased to $16-32 \mathrm{mg} / \mathrm{L}$ when plates were read at $48 \mathrm{~h}$. Such a large ( $>32$-fold) increase in MIC obtained simply by extending the incubation time from 24 to $48 \mathrm{~h}$ could be accounted for by the presence of a slowly growing subpopulation of bacteria highly resistant to imipenem. Microcolonies were faintly visible at $24 \mathrm{~h}$, but could not properly be enumerated before at least $48 \mathrm{~h}$ of incubation. A similar situation was observed at the end of time 
kill studies performed with imipenem $8 \mathrm{mg} / \mathrm{L}$. After $24 \mathrm{~h}$ incubation, tubes contained a majority of faintly visible microcolonies which, following further growth and suspension in MHB-S showed high resistance to imipenem (MIC: $32 \mathrm{mg} / \mathrm{L}$ ) in the macrodilution broth method.

Two experiments were performed in vivo to study the selection or induction of imipenem resistance during imipenem therapy. In the first experiment, six animals were treated twice a day for 4 days with imipenem $80 \mathrm{mg} / \mathrm{kg}$ and the number of imipenemresistant cells, namely those able to grow on agar supplemented with imipenem $8 \mathrm{mg} / \mathrm{L}$, were scored before and after therapy. In 16 TCF samples, containing at least $10^{5} \mathrm{cfu} / \mathrm{mL}$ at the onset of therapy, the median frequency of highly resistant organisms was $2.8 \times 10^{-4}$ (range $2.8 \times 10^{-5}-1.0 \times 10^{-3}$ ). After 4 days of therapy, the median frequency of imipenem-resistant organisms increased to $1.5 \times 10^{-2}$ (range $\left.1.3 \times 10^{-3}-10^{-1}\right)$.

A second therapeutic trial, using a higher imipenem dose $(120 \mathrm{mg} / \mathrm{kg})$ administered twice a day, for 7 days essentially confirmed the findings of the first trial. Whereas before therapy (day 1 ), the median proportion of highly resistant organisms was $1.3 \times 10^{-4}$ (range $0.4-4.1 \times 10^{-4}$ ), this value rose to $2.3 \times 10^{-3}$ (range $1.0 \times 10^{-4}$ to $4.0 \times 10^{-2}$ ) after therapy. Taken together, both therapeutic trials demonstrated the persistence of a highly resistant subpopulation of MRSA during high dose therapy of chronically infected tissue cages.

\section{Discussion}

The major objective of this study was to compare the activity of imipenem against methicillin-susceptible (MSSA) and methicillin-resistant (MRSA) strains of S. aureus in an experimental model of chronic tissue cage infections (Lucet et al., 1990), which represent a significant challenge to antimicrobial therapy (Chuard et al., 1991a). In-vitro studies have reported high antimicrobial activity (Wise, Andres \& Patel, 1981; Witte et al., 1982) of imipenem against methicillin-susceptible strains of $S$ aureus and pharmacokinetic studies (Drusano, 1986; Wise et al., 1986) have shown that it is possible to achieve high levels in humans and animals, suitable for therapy of Gram-positive bacterial infections. In an experimental model of staphylococcal infection, namely aortic-valve endocarditis in rats (Baumgartner \& Glauser, 1983) and rabbits (Apellaniz et al., 1991), the activity of imipenem was recorded as at least equivalent to that of the standard agent, cloxacillin, and even to that of cloxacillingentamicin combination therapy. Our results, which demonstrate significant imipenem activity against tissue cage infection by MSSA strain I20, agree with those previously reported for this antibiotic in both animals and humans. Although imipenem is not considered as a first line agent with which to treat staphylococcal infections, because of its lack of selectivity, a number of experimental and clinical observations have provided arguments for its clinical efficacy against MSSA strains.

An interesting and useful feature of imipenem is high resistance to $\beta$-lactamases. High levels of $\beta$-lactamase have recently been documented in so-called borderlinesusceptible strains of $S$. aureus (Kernodle \& Kaiser, 1993), which are devoid of intrinsic methicillin-resistance. High production of $\beta$-lactamase by MSSA strain 120 was recently observed (Berger-Bächi, B., personal communication), after completion of this study. It is therefore possible that the high amounts of $\beta$-lactamase produced by MSSA strain I20 decreased, in part, the efficacy of oxacillin against the chronically infecting 
strain. In contrast, the high stability of imipenem to $\beta$-lactamase hydrolysis is likely to have contributed to the good activity of this agent against MSSA strain 120.

The lack of activity of imipenem against MRSA strain MRGR3 in the rat model of chronic infection was not anticipated, in view of pilot in-vitro tests performed in standard conditions and because of the favourable pharmacokinetic properties of this antimicrobial agent administered at a high dose regimen $(120 \mathrm{mg} / \mathrm{kg})$. One significant factor which contributed to the failure of therapy was the emergence of a highly resistant subpopulation which grew slowly in the presence of antibiotic. The detection of such slow-growing imipenem-resistant colonies turned out to be difficult, because it required a long incubation time for accurate quantification of these organisms. Surprisingly, the addition of sodium chloride to the growth medium or the use of a lower temperature of incubation, as usually recommended for the detection of oxacillin resistance, was not useful in the imipenem context, because neither of these modifications shortened the time of incubation required for detection of imipenem resistant organisms.

When the in-vitro and in-vivo data were compared with those in the literature, we also found that detection of imipenem resistance had been an important part of some earlier studies (Berry et al., 1986; Chandrasekar et al., 1988). Whereas Chandrasekar et al. (1988) grew MRSA for $18-24 \mathrm{~h}$ at $35^{\circ} \mathrm{C}$ on mannitol and sodium chloridesupplemented agar and found good in-vitro and in-vivo activity of imipenem against these organisms, opposite results and conclusions were obtained by Berry et al. (1986) who enumerated colonies of methicillin-resistant Stapylococcus epidermidis after $72 \mathrm{~h}$ of growth at $30^{\circ} \mathrm{C}$. These major differences in incubation times and temperatures could afford an explanation for the conflicting results obtained from the studies, in particular because the former group selected a $24 \mathrm{~h}$ growing period which was likely to have been insufficient to detect the slow-growing, highly resistant subpopulations of MRSA.

In conclusion, imipenem showed good activity in an experimental model of chronic foreign body-associated infection caused by a methicillin-susceptible strain of $S$. aureus. However, the lack of activity of imipenem against the methicillin-resistant strain of $S$. aureus in the same model and the observation that an imipenem-resistant subpopulation grew very slowly and could easily be overlooked in standard culture and susceptibility testing conditions, are further indications that this antibacterial agent should not be used for therapy of chronic foreign body infections caused by MRSA.

\section{Acknowledgements}

This work was supported in part by a research grant from MSD, Glattbrugg, Switzerland and by grant 32-30161.90 from the Swiss National Research Foundation. C. Chuard is the recipient of fellowship 32-27222.89 from the Swiss National Research Foundation. We thank Manuela Bento for outstanding technical assistance.

\section{References}

Apellaniz, G., Valdes, M., Perez, R., Martin, F., Soria, F., Garcia, A., Gomez, J. \& Vicente. T. (1991). Comparison of the effectiveness of various antibiotics in the treatment of methicillinsusceptible Staphylococcus aureus experimental infective endocarditis. Journal of Chemotherapy 3, 91-7.

Baumgartner, J. D. \& Glauser, M. P. (1983). Comparative imipenem treatment of Staphylococcus aureus endocarditis in the rat. Journal of Antimicrobial Chemotherapy 12 , Suppl. D. 79-87. 
Berry, A. J., Johnson, J. L. \& Archer, G. L. (1986). Imipenem therapy of experimental Staphylococcus epidermidis endocarditis. Antimicrobial Agents and Chemotherapy 29, $748-52$.

Bisno, A. L. (1989). Infections of central nervous system shunts. In Infections Associated with Indwelling Medical Devices (Bisno, A. L. \& Waldvogel, F. A., Eds), pp. 93-109. American Society for Microbiology, Washington, DC.

Brause, B. D. (1989). Infected orthopedic prostheses. In Infections Associated with Indwelling Medical Devices (Bisno, A. L. \& Waldvogel, F. A., Eds), pp. 111-27. American Society for Microbiology, Washington, DC.

Brumfit, W. \& Hamilton-Miller, J. (1989). Methicillin-resistant Staphylococcus aureus. New England Journal of Medicine 320, 1188-96.

Calandra, G. B., Wang, C., Aziz, M. \& Brown, K. R. (1986). The safety profile of imipenem/ cilastatin: worldwide clinical experience based on 3470 patients. Journal of Antimicrobial Chemotherapy 18, Suppl. E, 193-202.

Chambers, H. F. (1988). Methicillin-resistant staphylococci. Clinical Microbiology Reviews 1, $173-86$.

Chandrasekar, P. H., Levine, D. P., Proce, S. \& Ryback, M. J. (1988). Comparative efficacies of imipenem-cilastatin and vancomycin in experimental aortic valve endocarditis due to methicillin resistant Staphylococcus aureus. Journal of Antimicrobial Chemotherapy 21, $461-9$.

Chuard, C., Hermann, M., Vaudaux, P., Waldvogel, F. A. \& Lew, D. P. (199la). Successful therapy of experimental chronic foreign-body infection due to methicillin-resistant Staphylococcus aureus by antimicrobial combinations. Antimicrobial Agents and Chemotherapy 35, 2611-6.

Chuard, C., Lucet, J. C., Rohner, P., Herrmann, M., Auckenthaler, R., Waldvogel, F. A. \& Lew, D. P. (1991b). Resistance of Staphylococcus aureus recovered from infected foreign body in vivo to killing by antimicrobials. Journal of Infectious Diseases 163, 1369-73.

Chuard, C., Rohner, P., Dunand, V., Auckenthaler, R. \& Lew, D. P. (1992). In-vitro and in-vivo evaluation of the antistaphylococcal activity of S-5556, a new 16-membered macrolide. Journal of Antimicrobial Chemotherapy 30, 327-37.

Drusano, G. L. (1986). An overview of pharmacology of imipenem/cilastatin. Journal of Antimicrobial Chemotherapy 18, Suppl. E, 79-92.

Fan, W., del Busto, R., Lore, M., Markowitz, C., Cendrowski, C., Cardenas, J., Quinn, E. \& Saravolatz, L. (1986). Imipenem-cilastatin in the treatment of methicillin-sensitive methicillin-resistant Staphylococcus aureus infections. Antimicrobial Agents and Chemotherapy 29, 26-9.

Gristina, A. G. \& Costerton, J. W. (1985). Bacterial adherence to biomaterials and tissues. Journal of Bone and Joint Surgery 67A, 264-73.

Karchmer, A. W. \& Bisno, A. L. (1989). Infections of prosthetic heart valves and vascular grafts. In Infections Associated With Indwelling Medical Devices (Bisno, A. L. \& Waldvogel, F. A., Eds), pp. 129-59. American Society for Microbiology, Washington, DC.

Kernodle, D. S. \& Kaiser, A. B. (1993). Efficacy of prophylaxis with beta-lactams and betalactam-beta-lactamase inhibitor combinations against wound infection by methicillinresistant and borderline-susceptible Stapylococcus aureus in a guinea pig model. Antimicrobial Agents and Chemotherapy 37, 702-7.

Lucet, J.-C., Hermann, M., Rohner, P., Auckenthaler, R., Waldvogel, F. A. \& Lew, D. P. (1990). Treatment of experimental foreign body infection caused by methicillin-resistant Staphylococcus aureus. Antimicrabial Agents and Chemotherapy 34, 2312-7.

National Committee for Clinical Laboratory Standards. (1987). Methods for Determining Bactericidal Activity of Antimicrobial Agents; Approved Standard M26-P. NCCLS, Villanova, PA.

Rohner, P., Peebo, M., Lew, D. P., Auckenthaler, R. \& Pechère, J. C. (1992). Comparative in-vitro activity of new quinolones against clinical isolates and resistant mutants. Journal of Antimicrobial Chemotherapy 29, 41-8.

Rosner, B. (1990). Fundamental of Biostatistics. PWS-Kent Publishing Company, Boston, MA.

Vaudaux, P. E., Lew, D. P. \& Waldvogel, F. A. (1989). Host factors predisposing to foreign body infections. In Infections Associated with Indwelling Medical Devices (Bisno, A. L. \& Waldvogel, F. A., Eds), pp. 3-26. American Society for Microbiology, Washington, DC. 
Wise, R., Andres, J. M. \& Patel, N. (1981). N-formimidoyl thienamycin, a novel beta-lactam: an in vitro comparison with other beta-lactam antibiotics. Journal of Antimicrobial Chemotherapy 7, 521-9.

Wise, R., Donovan, I. A., Lockeley, M. R., Drumm, J. \& Andrews, J. M. (1986). The pharmacokinetics and tissue penetration of imipenem. Journal of Antimicrobial Chemotherapy 18, Suppl. E. 93-101.

Witte, J. L., Sapico, F. L. \& Canawati, H. N. (1982). In vitro susceptibility of methicillinresistant and methicillin-susceptible Staphylococcus aureus strains to $\mathrm{N}$-formimidoyl thienamycin. Antimicrobial Agents and Chemotherapy 22, 906-8.

Zimmerli, W., Lew, D. P. \& Waldvogel, F. A. (1984). Pathogenesis of foreign body infection. Evidence of a local granulocyte defect. Journal of Clinical Investigation 73, 1191-200.

(Received 28 July 1993; revised version accepted 13 January 1994) 